\title{
Editorial: Genome-Wide Analyses of Pectobacterium and Dickeya Species
}

\author{
Mohammad Arif ${ }^{1 *}$, Robert Czajkowski ${ }^{2 *}$ and Toni A. Chapman ${ }^{3 *}$ \\ ${ }^{1}$ Department of Plant and Environmental Protection Sciences, University of Hawaii at Manoa, Honolulu, HI, United States, \\ ${ }^{2}$ Laboratory of Biologically Active Compounds, Intercollegiate Faculty of Biotechnology UG and MUG, University of Gdansk, \\ Gdańsk, Poland, ${ }^{3}$ Biosecurity and Food Safety, NSW Department of Primary Industries, Elizabeth Macarthur Agricultural \\ Institute (EMAl), Menangle, NSW, Australia
}

Keywords: pectinolytic bacteria, soft rot and blackleg disease, Dickeya, Pectobacterium, genome-wide, comparative genomics

\section{Editorial on the Research Topic}

\section{Genome-Wide Analyses of Pectobacterium and Dickeya Species}

Pectobacterium and Dickeya, emerging pathogens and key genera included in the Soft Rot Pectobacteriaceae family (SRP; formerly known as pectinolytic Erwinia spp.) (Adeolu et al., 2016), are among the top 10 bacterial plant pathogens that limit crop yields and threaten global food security worldwide (Mansfield et al., 2012). Species within both genera are globally distributed (Mansfield et al., 2012; Ma et al., 2019; Boluk et al., 2021) and cause significant damage to both monocots and dicots, particularly to potato with potential global losses in production (Agrios,

OPEN ACCESS

Edited and reviewed by: Adam Schikora, Julius Kühn Institute (JKI), Germany

${ }^{*}$ Correspondence: Mohammad Arif arif@hawaii.edu

Robert Czajkowski robert.czajkowski@ug.edu.pl Toni A. Chapman toni.chapman@dpi.nsw.gov.au

Specialty section: This article was submitted to Plant Pathogen Interactions, a section of the journal Frontiers in Plant Science

Received: 15 January 2022 Accepted: 20 January 2022 Published: 03 March 2022

Citation:

Arif M, Czajkowski R and Chapman TA (2022) Editorial: Genome-Wide Analyses of Pectobacterium and

Dickeya Species.

Front. Plant Sci. 13:855262. doi: 10.3389/fp/s.2022.855262 2006), and an estimated cost of US\$50-100 million annually in vegetables, fruits, and ornamental plants (Perombelon and Kelman, 1980; Pérombelon, 2002; Ma et al., 2007). Species in both genera have been isolated from infected plant tissues, soil, and water (Glasner et al., 2008; HugouvieuxCotte-Pattat et al., 2019; Oulghazi et al., 2019) as well as from alternative non-agricultural plant hosts (Fikowicz-Krosko et al., 2017; Fikowicz-Krosko and Czajkowski, 2018). The pectinolytic bacteria rapidly adapt to new hosts, raising serious concerns for potential damage to new crops (Boluk et al., 2020, 2021; Klair et al., 2021).

Recently, several new Pectobacterium and Dickeya species were reported; Pectobacterium is currently divided into 19 recognized species with the addition of $P$. parvum in 2020 (Pasanen et al., 2020), and Dickeya is divided into 12 species, including the recent addition of D. oryzae (Wang et al., 2020).

High levels of virulence associated with these SRPs involves the secretion of plant cell wall degrading enzymes (PCWDEs) primarily through a type II secretion system (T2SS), enabling them to digest their hosts more extensively than any other microbes in both field and storage conditions (Hugouvieux-Cotte-Pattat et al., 2014; Li et al., 2018; Arizala and Arif, 2019; Fan et al., 2020). Pathogenicity determinants play a significant role in host adaptation and virulence (Boluk et al., 2021). PCWDEs and other virulence factors, such as the type III effector protein DspE and necrosis inducing protein Nip, are used to macerate plant tissue and promote plant cell death, providing nutrients for the multiplication and colonization of these necrotrophic pathogens (Kim et al., 2011; Babujee et al., 2012; Charkowski et al., 2012; Haque et al., 2017; Fan et al., 2020). The T1SS, T2SS, T6SS, some PCWDEs and proteases, the ECA cluster, achromobactin, flagellar genes, single virulence locus, the pilW and pilABC genes, Flp/Tad, carotovoricin, DsbA oxidoreductase, and the majority of virulence regulators were anticipated critical genes/gene clusters for all Pectobacterium species, while T3SS, T4SS, T5SS, phytotoxins, type IV pilus, capsular polysaccharide, lipopolysaccharides, exopolysaccharides, iron uptake systems, phenazine, carbapenem, and colicin-like bacteriocins were observed in some species. Differences among 
antimicrobial compounds and toxin and antitoxin systems surrounding the CRISPR-Cas systems were observed in others (Glasner et al., 2008; Charkowski et al., 2012; Arizala and Arif, 2019; Przepiora et al., 2022).

Despite the severe disease impact of Pectobacterium and Dickeya species, not many comprehensive studies of SRPs have been conducted to ascertain evolutionary relationships among strains or the role of horizontal gene transfer (HGT) in speciation and adaptation to a new niche. Likewise, the impact of phages and prophages on the ecology and virulence of Pectobacterium and Dickeya still needs to be assessed in detail to understand the role of these virus-bacteria interactions in natural and agricultural settings (Czajkowski, 2016, 2019).

Rapidly developing sequencing technology (Illumina, Ion Torrent, Pacific Biosciences and Oxford Nanopore) has led to a sharp decrease in sequencing costs and has enabled genome sequencing of plant bacterial strains on a vast scale. Genomics analyses play a dominant role in elucidating bacterial taxonomy, phylogeny, and evolutionary biology and provide insights into distinct niche adaptation (McAdam et al., 2014; Cai et al., 2018; Arizala and Arif, 2019). Comparative genomics of recently evolved or emerging pathogens provide insights into the regions/islands acquired by closely related strains, enabling them to adapt to a new host/environment (Zhang et al., 2020). The number of new "omics datasets-such as genome sequencing, RNA-seq, pan-genomics, and metabolomics-are increasing rapidly. New bioinformatics pipelines and software have also become available, and with the increasing numbers of datasets and bioinformatics pipelines and software, we can accelerate the progress made in comparative and functional bacterial genomics (Chen et al., 2017; Karp et al., 2019).

In this special issue, six articles were published. Czajkowski et al. in their article "Genome-wide identification of Dickeya solani transcriptional units upregulated in response to plant tissues from a crop-host Solanum tuberosum and a weed-host Solanum dulcamara", identified 210 mutant of D. solani IPO 2222 exhibited plant tissue-dependent expression. The selected 13 genes were differentially expressed in potato (Solanum tuberosum) and/or Solanum dulcamara (bittersweet nightshade) stem, leaf, and root tissues. These results imply that necrotrophic bacterium $D$. solani can recognize its hosts during the early stages of infection and modify its behavior accordingly. In the next article "The PhoPQ two-component system is the major regulator of cell surface properties, stress responses, and plant-derived substrate utilization during development of Pectobacterium versatile-host plant pathosystems" by Kravchenko et al. it was revealed that PhoP, part of PhoPQ two compartment system, regulates at least 115 genes involved in degradation, transport, and metabolism of plant-derived carbon sources, bacterial cell envelope, and stress resistance, and concluded that PhoPQ is a crucial system regulating multiple virulencerelated genes controlling the development of $P$. versatilehost plant pathosystem. Article "Pectobacterium brasiliense 1692 chemotactic responses and the role of methyl-accepting chemotactic proteins in ecological fitness" by Tanui et al. identified 34 methyl-accepting chemotactic proteins (MCPs) in $P$. brasiliense $\mathrm{Pb}$ 1692. Four out of $34 \mathrm{MCPs}$ were further characterized and found that these MCPs contribute toward the biology and fitness of $\mathrm{Pb} 1692$ during potato infection. Pun et al. in their article "Phloretin, an apple phytoalexin, affects the virulence and fitness of $P$. brasiliense by interfering with quorumsensing" described that biofilm formation, secretion of plant cell wall-degrading enzymes, and production of acyl-homoserine lactone (AHL) signaling molecules were significantly inhibited by exposing $P$. brasiliense to phloretin, and impaired virulence mechanisms. The results support that phloretin inhibits Expl activity. Genomic biology of two unique strains of Dickeya zeae was described in the article "Genomic and phenotypic biology of novel strains of $D$. zeae isolated from pineapple and taro in Hawaii: insights into genome plasticity, pathogenicity, and virulence determinants" by Boluk et al.. The analyses revealed truncated type III and IV secretion systems (T3SS and T4SS) in the taro strain. Both strains, from pineapple and taro, however, were pathogenic, lacking the zeamine biosynthesis gene cluster, a key player in virulence in other Dickeya spescies. In the last article "Transcriptome analysis revealed overlapping and special regulatory roles oVf RpoN1 and RpoN2 in motility, virulence, and growth of Xanthomonas oryzae pv. oryzae" by Yu et al. it was found that deletion of rpoN1 or rpoN2 in X. oyzae pv. oryzae led to significant disfunction of bacterial swimming motility, flagellar assembly, and virulence, and identified 127 overlapping differentially expressed genes (DEGs) regulated by both RpoN1 and RpoN2.

In conclusion, this special issue compiled research articles covering comparative and functional genomics analysis of SRP bacteria. The articles published in this issue added scientific knowledge to fill information gaps related to pathogenicity determinants, genetic exchange, and evolution of this devastating group of pathogens, and enhanced our ability to combat soft rot diseases that unequivocally impact food security.

\section{AUTHOR CONTRIBUTIONS}

All authors listed have made a substantial, direct, and intellectual contribution to the work and approved it for publication.

\section{FUNDING}

MA acknowledges the support by NIGMS of the National Institutes of Health under award number P20GM125508. RC acknowledges the grant support of NCN OPUS $13(2017 / 25 / B / N Z 9 / 00036)$ from the National Science Center, Poland (Narodowe Centrum Nauki, Polska). TC acknowledges the support by the NSW Department of Primary Industries, Australia.

\section{ACKNOWLEDGMENTS}

We thank all authors and reviewers for their contribution. 


\section{REFERENCES}

Adeolu, M., Alnajar, S., Naushad, S., and Gupta, R. S. (2016). Genomebased phylogeny and taxonomy of the 'Enterobacteriales': proposal for Enterobacterales ord. nov. divided into the families Enterobacteriaceae, Erwiniaceae fam. nov., Pectobacteriaceae fam. nov., Yersiniaceae fam. nov., Hafniaceae fam. nov., Morganellaceae fam. nov., and Budviciaceae fam. nov. Int. J. Syst. Evol. Microbiol. 66, 5575-5599. doi: 10.1099/ijsem.0.001485

Agrios, G. N. (2006). Bacterial Soft Rots, 5th Edn. San Diego, CA: Academic Press.

Arizala, D., and Arif, M. (2019). Genome-wide analyses revealed remarkable heterogeneity in pathogenicity determinants, antimicrobial compounds, and CRISPR-Cas systems of complex phytopathogenic genus Pectobacterium. Pathogens. 8, 247. doi: 10.3390/pathogens8040247

Babujee, L., Apodaca, J., Balakrishnan, V., Liss, P., Kiley, P. J., Charkowski, A. O., et al. (2012). Evolution of the metabolic and regulatory networks associated with oxygen availability in two phytopathogenic enterobacteria. BMC Genom. 13, 110. doi: 10.1186/1471-2164-13-110

Boluk, G., Arizala, D., Dobhal, S., Zhang, J., Hu, J., Alvarez, A. M., et al. (2021). Genomic and phenotypic biology of novel strains of Dickeya zeae isolated from pineapple and taro in Hawaii: insights into genome plasticity, pathogenicity, and virulence determinants. Front. Plant Sci. 12, 663851. doi: $10.3389 /$ fpls.2021.663851

Boluk, G., Arizala, D., Ocenar, J., Mokwele, J., Silva, J., Dobhal, S., et al. (2020). First report of Pectobacterium brasiliense causing soft rot on Brassica oleracea var. sabellica L. in Hawaii, United States. Plant Dis. 2721. doi: 10.1094/PDIS-04-20-0701-PDN

Cai, H., Bai, Y., and Guo, C. (2018). Comparative genomics of 151 plant-associated bacteria reveal putative mechanisms underlying specific interactions between bacteria and plant hosts. Genes Genom. 40, 857-864. doi: 10.1007/s13258-018-0693-1

Charkowski, A., Blanco, C., Condemine, G., Expert, D., Franza, T., Hayes, C., et al. (2012). The role of secretion systems and small molecules in softrot Enterobacteriaceae pathogenicity. Annu. Rev. Phytopathol. 50, 425-449. doi: 10.1146/annurev-phyto-081211-173013

Chen, I. A., Markowitz, V. M., Chu, K., Palaniappan, K., Szeto, E., Pillay, M., et al. (2017). IMG/M: integrated genome and metagenome comparative data analysis system. Nuc. Acids Res. 45, D507-D516. doi: 10.1093/nar/gkw929

Czajkowski, R. (2016). Bacteriophages of soft rot Enterobacteriaceae-a minireview. FEMS Microbiol. Lett. 363, fnv230. doi: 10.1093/femsle/fnv230

Czajkowski, R. (2019). May the phage be with you? Prophage-like elements in the genomes of soft rot Pectobacteriaceae: Pectobacterium spp. and Dickeya spp. Front. Microbiol. 10, 138. doi: 10.3389/fmicb.2019.00138

Fan, J., Ma, L., Zhao, C., Yan, J., Che, S., Zhou, Z., et al. (2020). Transcriptome of Pectobacterium carotovorum subsp. carotovorum Pcc51 infected in calla plants in vivo highlights a spatiotemporal expression pattern of genes related to virulence, adaptation, and host response. Mol Plant Pathol. 21, 871-889. doi: $10.1111 / \mathrm{mpp} .12936$

Fikowicz-Krosko, J., and Czajkowski, R. (2018). Systemic colonization and expression of disease symptoms on bittersweet nightshade (Solanum dulcamara) infected with a GFP-tagged Dickeya solani IPO2222 (IPO2254). Plant Dis. 102, 619-627. doi: 10.1094/PDIS-08-17-1147-RE

Fikowicz-Krosko, J., Wszalek-Rozek, K., Smolarska, A., and Czajkowski, R. (2017). First report of isolation of soft rot Pectobacterium carotovorum subsp. carotovorum from symptomless bittersweet nightshade occuring in rural area of Poland. J. Plant Pathol. 99:294. doi: 10.4454/jpp.v99i1.3772

Glasner, J. D., Marquez-Villavicencio, M., Kim, H.-S., Jahn, C. E., Ma, B., Biehl, B. S., et al. (2008). Niche-specificity and the variable fraction of the Pectobacterium pan-genome. Mol. Plant Microbe Interact. 21, 1549-1560. doi: 10.1094/MPMI-21-12-1549

Haque, M. M., Oliver, M. M. H., Nahar, K., Alam, M. Z., Hirata, H., and Tsuyumu, S. (2017). CytR homolog of Pectobacterium carotovorum subsp. carotovorum controls air-liquid biofilm formation by regulating multiple genes involved in cellulose production, c-di-GMP signaling, motility, and type Ill secretion system in response to nutritional and environmental signals. Front. Microbiol. 8, 972. doi: $10.3389 /$ fmicb.2017.00972

Hugouvieux-Cotte-Pattat, N., Condemine, G., and Shevchik, V. E. (2014). Bacterial pectate lyases, structural and functional diversity: bacterial pectate lyases. Environ. Microbiol. 6, 427-440. doi: 10.1111/1758-2229.12166
Hugouvieux-Cotte-Pattat, N., Jacot-des-Combes, C., and Briolay, J. (2019). Dickeya lacustris sp. nov., a water-living pectinolytic bacterium isolated from lakes in France. Int. J. Syst. Evol. Microbiol. 69, 721-726. doi: 10.1099/ijsem.0.003208

Karp, D. P., Ivanova, N., Krummenacker, M., Kyrpides, N., Latendresse, M., Midford, P., et al. (2019). A comparison of microbial genome web portals. Front. Microbiol. 10, 208. doi: 10.3389/fmicb.2019. 00208

Kim, H. S., Thammarat, P., Lommel, S. A., Hogan, C. S., and Charkowski, A. O. (2011). Pectobacterium carotovorum elicits plant cell death with DspE/F but the P. carotovorum DspE does not suppress callose or induce expression of plant genes early in plant-microbe interactions. Mol. Plant Microbe Int. 24, 773-786. doi: 10.1094/MPMI-06-10-0143

Klair, D., Silva, J., Arizala, D., Boluk, G., Dobhal, S., Ahmad, A. A., et al. (2021). First Report of Pectobacterium brasiliense causing soft rot on mizuna (Brassica rapa var. japonica) in the United States. Plant Dis. 4149. doi: 10.1094/PDIS-03-21-0644-PDN

Li, X., Ma, Y., Liang, S., Tian, Y., Yin, S., Xie, S., et al. (2018). Comparative genomics of 84 Pectobacterium genomes reveals the variations related to a pathogenic lifestyle. BMC Genom. 19, 889. doi: 10.1186/s12864-018-5269-6

Ma, B., Hibbing, M. E., Kim, H. S., Reedy, R. M., Yedidia, I., Breuer, J., et al. (2007). Host range and molecular phylogenies of the soft rot entero-bacterial genera Pectobacterium and Dickeya. Phytopath. 97, 1150-1163. doi: 10.1094/PHYTO-97-91150

Ma, X., Perna, N. T., Glasner, J. D., Hao, J., Johnson, S., Nasaruddin, A. S., et al. (2019). Complete genome sequence of Dickeya dianthicola ME23, a pathogen causing blackleg and soft rot diseases of potato. Microbiol. Resour. Announc. 8, e01526-e01518. doi: 10.1128/MRA.015 26-18

Mansfield, J., Genin, S., Magori, S., Citovsky, V., Sriariyanum, M., Ronald, M., et al. (2012). Top 10 plant pathogenic bacteria in molecular plant pathology. Mol. Plant Pathol. 13, 614-629 doi: 10.1111/j.1364-3703.2012.00 804.x

McAdam, P. R., Richardson, E. J., and Fitzgerald, J. R. (2014). Highthroughput sequencing for the study of bacterial pathogen biology. Curr. Opin. Microbiol. 19, 106-113. doi: 10.1016/j.mib.2014.0 6.002

Oulghazi, S., Pédron, J., Cigna, J., Lau, Y. Y., Moumni, M., Van Gijsegem, F., et al. (2019). Dickeya undicola sp. nov., a novel species for pectinolytic isolates from surface waters in Europe and Asia. Int. J. Syst. Evol. Microbiol. 69, 2440-2444. doi: 10.1099/ijsem.0.00 3497

Pasanen, M., Waleron, M., Schott, T., Cleenwerck, I., Misztak, A., Waleron, K., et al. (2020). Pectobacterium parvum sp. nov., having a Salmonella SPI-1-like Type III secretion system and low virulence. Int. J. Syst. Evol. Microbiol. 70, 2440-2448. doi: 10.1099/ijsem.0.00 4057

Pérombelon, M. C. M. (2002). Potato diseases caused by soft rot erwinias: an overview of pathogenesis. Plant Pathol. 51, 1-12. doi: 10.1046/j.0032-0862.2001.Short title.doc.x

Perombelon, M. C. M., and Kelman, A. (1980). Ecology of the Soft Rot Erwinias. Annu. Rev. Phytopath. 18, 361-387. doi: 10.1146/annurev.py.18.090180.002045

Przepiora, T., Figaj, D., Bogucka, A., Fikowicz-Krosko, J., Czajkowski, R., Hugouvieux-Cotte-Pattat, N., et al. (2022). The periplasmic oxidoreductase DsbA is required for virulence of the phytopathogen Dickeya solani. Int. J. Mol. Sci. 23, 697. doi: 10.3390/ijms 23020697

Wang, X., He, S.-W., Guo, H.-B., Han, J.-G., Thin, K. K., Gao, J.S., et al. (2020). Dickeya oryzae sp. nov., isolated from the roots of rice. Int. J. Syst. Evol. Microbiol. 70, 4171-4178. doi: 10.1099/ijsem.0. 004265

Zhang, J., Arif, M., Shen, H., Hu, J., Sun, D., Pu, X., et al. (2020). Genomic divergence between Dickeya zeae strain EC2 isolated from rice and previously identified strains, suggests a different rice foot rot strain. PLOS ONE 15, e0240908. doi: 10.1371/journal.pone.0240908

Author Disclaimer: The content is solely the responsibility of the authors and does not necessarily represent the official views of the funding agencies. 
Conflict of Interest: The authors declare that the research was conducted in the absence of any commercial or financial relationships that could be construed as a potential conflict of interest.

Publisher's Note: All claims expressed in this article are solely those of the authors and do not necessarily represent those of their affiliated organizations, or those of the publisher, the editors and the reviewers. Any product that may be evaluated in this article, or claim that may be made by its manufacturer, is not guaranteed or endorsed by the publisher.

Copyright (c) 2022 Arif, Czajkowski and Chapman. This is an open-access article distributed under the terms of the Creative Commons Attribution License (CC BY). The use, distribution or reproduction in other forums is permitted, provided the original author(s) and the copyright owner(s) are credited and that the original publication in this journal is cited, in accordance with accepted academic practice. No use, distribution or reproduction is permitted which does not comply with these terms. 